\title{
Glucose Oxidase Induces Cellular Senescence in Immortal Renal Cells through ILK by Downregulating Klotho Gene Expression
}

\author{
Nuria Troyano-Suárez, ${ }^{1}$ María del Nogal-Avila, ${ }^{2}$ Inés Mora, ${ }^{1}$ \\ Patricia Sosa, ${ }^{1}$ Susana López-Ongil, ${ }^{3,4}$ Diego Rodriguez-Puyol, ${ }^{3,4}$ \\ Gemma Olmos, ${ }^{1,4}$ and María Piedad Ruíz-Torres ${ }^{1,4}$ \\ ${ }^{1}$ Departamento de Biología de Sistemas, Universidad de Alcalá, Alcalá de Henares, 28871 Madrid, Spain \\ ${ }^{2}$ University of Alabama at Birmingham, Birmingham, AL, USA \\ ${ }^{3}$ Unidad de Investigación, Fundación para la Investigación Biomédica del Hospital Universitario Príncipe de Asturias, \\ Alcalá de Henares, 28871 Madrid, Spain \\ ${ }^{4}$ Instituto Reina Sofía de Investigación Nefrológica, IRSIN, Madrid, Spain
}

Correspondence should be addressed to María Piedad Ruíz-Torres; mpiedad.ruiz@uah.es

Received 8 April 2015; Accepted 17 May 2015

Academic Editor: Claudio Cabello-Verrugio

Copyright (C) 2015 Nuria Troyano-Suárez et al. This is an open access article distributed under the Creative Commons Attribution License, which permits unrestricted use, distribution, and reproduction in any medium, provided the original work is properly cited.

Cellular senescence can be prematurely induced by oxidative stress involved in aging. In this work, we were searching for novel intermediaries in oxidative stress-induced senescence, focusing our interest on integrin-linked kinase (ILK), a scaffold protein at cell-extracellular matrix (ECM) adhesion sites, and on the Klotho gene. Cultured renal cells were treated with glucose oxidase (GOx) for long time periods. GOx induced senescence, increasing senescence associated $\beta$-galactosidase activity and the expression of p16. In parallel, GOx increased ILK protein expression and activity. Ectopic overexpression of ILK in cells increased p16 expression, even in the absence of GOx, whereas downregulation of ILK inhibited the increase in p16 due to oxidative stress. Additionally, GOx reduced Klotho gene expression and cells overexpressing Klotho protein did not undergo senescence after GOx addition. We demonstrated a direct link between ILK and Klotho since silencing ILK expression in cells and mice increases Klotho expression and reduces p53 and p16 expression in renal cortex. In conclusion, oxidative stress induces cellular senescence in kidney cells by increasing ILK protein expression and activity, which in turn reduces Klotho expression. We hereby present ILK as a novel downregulator of Klotho gene expression.

\section{Introduction}

Cellular senescence is a permanent cell cycle arrest accompanied by the alteration of the cell structure and functions. Senescence can be promoted in response to stress stimuli that result in DNA damage or by the replicative life of cells. Senescence induction can have beneficial effects in pathologies such as cancer or wound healing; however, the permanent presence of senescent cells in several tissues can induce or increase some pathologies [1]. Cellular senescence was discovered by Hayflick and Moorhead [2], whose experiments showed the limited number of cell divisions in cultured cells. This limited proliferation of cells is promoted by a shortening of telomeres in a chromosome [3], which, if too short, can induce cell senescence [4]. Moreover, cell senescence can be induced by other telomere-independent mechanisms, such as oncogene activation [5], DNA damage [6], or stressful stimuli called stress-induced premature senescence $[7,8]$. Recent studies from our group have demonstrated that hyperosmolar stress induced by high glucose concentration and Amadori products promoted premature senescence in kidney cells [9, $10]$.

Senescent cells are not able to proliferate and present some morphological and biochemical changes, such as increased activity of $\beta$-galactosidase (SA- $\beta$-GAL) due to an increase in lysosomal content [11] and in the expression of cell cycle inhibitors such as p16 or p53 tumor suppressor genes. 
Oxidative stress is involved in many diseases, such as cancer and inflammation, and it plays a relevant role in aging [12-14]. The evidence that reactive oxygen species (ROS) are involved in the senescence process has been provided by the use of antioxidant compounds that can prevent or delay cellular senescence [15]. ROS such as $\mathrm{H}_{2} \mathrm{O}_{2}$ or superoxide anions produce acute damage to proteins, lipids, and DNA. In addition, some works have shown that they can induce aging by the activation of senescence genes through MAPK cascade and their downstream kinase effector p38 [16, 17] and replicative senescence [14]. Thus, it has been shown that ROS can downregulate Klotho $[18,19]$, an aging-related kidney-secreted hormone with antioxidant properties [20]. Klotho is a glucuronidase activity protein which acts as a coreceptor for fibroblast growth factor 23 (FGF23) and regulates phosphate homeostasis and IGF-1 signaling [2123]. Klotho is downregulated in chronic kidney diseases (CKD) where aging features are accelerated. In fact, Klothodeficient mice show multiple age-related pathologies and a short lifespan.

In the last years, the integrin-linked kinase protein (ILK) has emerged with a relevant role in kidney and vascular physiology and physiopathology, mediating a relationship between extracellular matrix (ECM) and intracellular processes. ILK is a protein which is part of a cytoplasmic multiprotein complex and mediates the interaction between ECM proteins and intracellular pathways by a serine-threonine kinase activity [24]. This interaction between ECM proteins and the integrin receptor activates ILK, which regulates cellular processes such as proliferation, survival, migration, and fibrosis [25, 26]. However, only few works have established a relationship between ILK and the senescence process [27, 28] and its role in the aging process is still unknown.

In the present work, we test the hypothesis that ROS induce premature cellular senescence in renal cells through the increase in ILK expression and activity and the downregulation of Klotho protein expression, which modulate the expression of senescence genes such as p16.

\section{Material and Methods}

2.1. Reagents. Culture plates, culture media, blueStar-prestained protein marker, BCA protein assay reagent, CLXposure films, and SuperSignal West Pico detection system were from Cultek (Thermo Fisher Scientific, Madrid, Spain). The secondary horseradish peroxidase-conjugated goat antimouse IgG was from Dako Cytomation (Glostrup, Denmark). The secondary horseradish peroxidase-conjugated goat anti-rabbit IgG was from Merck Millipore (Darmstadt, Germany). Acrylamide-bisacrylamide was from HispanlabPronadisa (Madrid, Spain). Electrophoresis equipment and PVDF membrane were from Bio-Rad Laboratories (Richmond, CA, USA). Protease inhibitor cocktail tablets were from Roche (Mannheim, Germany). The $\beta$-galactosidase substrate (C12FDG, 5-dodecanoyl-aminofluorescein di- $\beta$-Dgalactopyranoside), the mounting medium ProLong Gold antifade reagent with DAPI, Trizol reagent, OptiMEM medium, Lipofectamine, ILK siRNA, and negative control used as a nonsilencing control were from Life Technologies
(Paisley, UK). Polyclonal rabbit anti-p53 and monoclonal rabbit anti-p16 were from Abcam (Cambridge, UK). Polyclonal rabbit anti-ILK1, monoclonal rabbit antibodies for antiphospho-GSK-3 $\beta$ (Ser9) and anti-GSK-3 $\beta$, and the buffer kinase 10X, ATP, and GSK-3 $\beta$ fusion protein were from Cell Signaling Technology Inc. (Boston, MA, USA). Polyclonal rabbit anti-4-hydroxy-2-nonenal adducts were from Alexis (Farmingdale, NY, USA). Glucose oxidase, bovine serum albumin (BSA), polyclonal rabbit anti-actin, and monoclonal mouse anti-GAPDH were from Sigma-Aldrich-Fluka Chemical Co. (St. Louis, MO, USA).

2.2. Culture Cells. Immortal mouse cortical tubule (MCT) cells are a cultured line of proximal tubular cells harvested originally from the renal cortex of SJL mice [29]. The cells were maintained in culture in DMEM supplemented with penicillin $100 \mathrm{U} / \mathrm{mL}$ and streptomycin $100 \mu \mathrm{g} / \mathrm{mL}$ and $10 \%$ heat-inactivated fetal bovine serum (FBS) in an atmosphere of $95 \%$ air and $5 \% \mathrm{CO}_{2}$ at $37^{\circ} \mathrm{C}$, as previously described $[29,30]$. Embryonic kidney epithelial human cells, HEK293T cells, were purchased from American Type Culture Collection (Rockville, MD, USA) and they were grown in Eagle's Minimum Essential Medium supplemented with 10\% FBS. Culture media were changed every 2 days. For the experiments, both types of cells were treated with $2.5 \mathrm{mU} / \mathrm{mL}$ glucose oxidase (GOx) at different times.

2.3. Protein Extraction and Immunoblot Analysis. Total protein extracts from cultured cells were obtained by using the Lysis Buffer (20 mM Tris- $\mathrm{HCl}$ pH 7.5, $150 \mathrm{mM} \mathrm{NaCl}$, $1 \mathrm{mM}$ EGTA, $1 \mathrm{mM}$ EDTA, $0.1 \%$ sodium deoxycholate, $1 \%$ Triton X-100, and $10 \mathrm{mM}$ sodium pyrophosphate) containing a protease inhibitor cocktail. The resulting solution was spun at $13,000 \mathrm{rpm}$ for $30 \mathrm{~min}$ at $4^{\circ} \mathrm{C}$. The protein concentration was determined by BCA protein assay. Equal amounts of protein $(30 \mu \mathrm{g}$ protein/lane) from each sample were separated on SDS-polyacrylamide gels under reducing conditions and transferred onto PVDF membranes. Membranes were blocked with $5 \%$ nonfat dry milk or $5 \%$ BSA in Tween Tris buffered saline (TTBS) (20 mM Tris- $\mathrm{HCl}$ pH 7.5, 0.9\% NaCl, and $0.05 \%$ Tween 20 ) for $1 \mathrm{~h}$ at room temperature and then incubated overnight at $4^{\circ} \mathrm{C}$ with different specific antibodies for mouse (anti-p53, anti-p16, anti-ILK1, anti-phospho-GSK$3 \beta$ (Ser9), and anti-GSK-3 $\beta$ ). Phospho-GSK- $3 \beta$ and GSK-3 $\beta$ were used to measure ILK activity. After washing in TTBS, the membranes were incubated with horseradish peroxidaseconjugated goat anti-mouse IgG or goat anti-rabbit IgG as secondary antibodies. The immunoreactive bands were visualized with the SuperSignal West Pico detection system after $30 \mathrm{sec}$ of exposure to CL-Xposure films. Then blots were reblotted with a rabbit anti-actin antibody in order to normalize p53, p16, or ILK1 levels.

Proteins from kidney cortex portions were obtained using the Lysis Buffer and, after incubation on ice for $30 \mathrm{~min}$, tissues were homogenized and spun at $13,000 \mathrm{rpm}$ for $30 \mathrm{~min}$ at $4^{\circ} \mathrm{C}$.

2.4. Detection of Senescence Associated $\beta$-Galactosidase Activity by Fluorescence Confocal Microscopy. To determine 
cellular senescence, SA- $\beta$-GAL activity was measured by fluorescence confocal microscopy, using the fluorogenic substrate C12FDG [11, 31]. MCT cells grown in microscope cover glasses were treated with $33 \mu \mathrm{M}$ C12FDG for $4 \mathrm{~h}$. At the end of incubation, cells were washed twice with PBS and fixed with $4 \%$ paraformaldehyde for $15 \mathrm{~min}$. Subsequently, cells were washed again and mounted in ProLong Gold antifade reagent with DAPI overnight. Samples were analyzed using LEICA TCS-SP5 confocal microscope (Leica Microsystems; Wetzlar, Germany) at $488 \mathrm{~nm}$ argon laser to detect the fluorescence of SA- $\beta$-GAL activity and at $405 \mathrm{~nm}$ to detect DAPI. Pictures were obtained and fluorescence intensity was measured by densitometry by Image J software (http://rsbweb.nih.gov/ij/).

2.5. Transfection of ILK and Klotho. Subconfluent MCT cells $(60 \%$ to $80 \%$ confluent) cultured in 6-well plate were transfected with plasmids containing ILK or Klotho.

For transient transfection of ILK [32], cells were transfected with different doses of a plasmid containing ILK wild type $(0,1$, and $2 \mu \mathrm{g})$ (ILK-WT which was provided by Dr. S. Dedhar, University of British Columbia, Canada). Then, each one was mixed with Lipofectamine $(5 \mu \mathrm{L} /$ well $)$ and incubated for 15 minutes at room temperature for 24 hours prior to addition to the cells.

For stable transfection of Klotho [10,33], cells were transfected with $1 \mu \mathrm{g}$ of a plasmid containing the transmembrane form of mouse Klotho cloned into pEF1/Myc-His vector (pEF1-Klotho) or with the empty $\mathrm{pEF1/Myc-His} \mathrm{vector} \mathrm{as}$ control (pEF1-Empty). Both plasmids were kindly provided by Dr. M. Kuro-O from the University of Texas Southwestern Medical Center, Texas. For transfection, Opti-MEM media and Lipofectamine were used. To select the transfected MCT cells, cells were treated with $200 \mu \mathrm{g} / \mathrm{mL}$ of G418 (Invitrogen) for 14 days. Transfection of Klotho in HEK293T cells was transient as these cells have resistance to Geneticin and they cannot be selected with G418.

At the end of transfection, media were removed and replaced with complete media for $24 \mathrm{~h}$, after which MCT cells were lysed. Protein concentration was measured to analyze p16 protein levels by western blot, and RNA was isolated to test Klotho mRNA levels.

2.6. Measurement of mRNA Expression. The total RNA from MCT cells or kidney cortex from mice was isolated using Trizol reagents according to the manufacturer's protocol. The RNA integrity was checked using agarose-formaldehyde gels, and the RNA concentration was measured using a VisUV spectrophotometer (Nanodrop). cDNA was synthesized using a high capacity cDNA reverse transcription kit (Applied Biosystems Inc., Foster City, CA, USA), and Klotho, ILK-1, and GAPDH expression was measured by quantitative RTPCR (qPCR) (ABI Prism 7000), using Taqman genes and double delta Ct method. Klotho (Mm00473122_m1), ILK1 (Mm01274251_g1), and the endogenous control GAPDH (Mm99999915_g1) were used (Applied Biosystems Inc., Foster City, CA, USA).

2.7. ILK siRNA Transfection. ILK was silenced in MCT cells by transfecting a specific small interfering RNA against
ILK (siILK). An unspecific scrambled RNA was used as transfection control (scRNA). Both silLK and scRNA were transfected using Lipofectamine 2000 for $24 \mathrm{~h}$. Cells were incubated with complete RPMI for $24 \mathrm{~h}$. Cells were processed in duplicate to evaluate p16 expression by western blot after adding GOx for $48 \mathrm{~h}$ using serum-free RPMI and to check ILK and Klotho mRNA expression by RT-qPCR, as described above.

2.8. Conditional ILK Knockout Mouse Model. All animal procedures were in accordance with the EU Directive 2010/63/EU and they were previously approved by the Institutional Animal Care and Use Committee at the University of Alcala. Animals were housed in a pathogen-free and temperature-controlled room $\left(22 \pm 2^{\circ} \mathrm{C}\right)$. Food and water were available ad libitum. Conditional inactivation of the ILK gene was accomplished by crossing C57Bl/6 mice homozygous for the floxed ILK allele, flanked by loxP sites (ILKfl/fl), with homozygous mice carrying a tamoxifeninducible CreER $(\mathrm{T})$ recombinase gene $\left(\mathrm{CRE}^{+/+}\right)$which express Cre under the control of the cytomegalovirus promoter [34, 35]. Eight-week-old male mice were injected intraperitoneally with $1.5 \mathrm{mg}$ of tamoxifen (TX) (Sigma Co., St. Louis, MO, USA) (dissolved in a 10:1 volumetric mix of corn oil and ethanol) or Vehicle alone (VH), once a day for 5 consecutive days to induce ILK deletion. After 5,15 , and 30 days following VH or TX injections, routine genotyping of tail DNA samples was performed to monitor the Cre-driven ILK deletion [36, 37]. TX-treated CRE-LOX mice displaying successful deletion of ILK are named conditional KO-ILK (cKO-ILK) mice and their control VH-treated CRE-LOX are named wild type (WT). Animals were euthanized 20 days after the last injection.

The p16 and p53 expression in renal cortex from WT or cKO-ILK mice was assessed by western blot as well as ILK and Klotho mRNA levels by RT-qPCR in these samples, as described above.

2.9. Statistical Analysis. Results are shown as mean \pm standard error of the mean (s.e.m.) of a variable number of experiments, detailed in figure captions. Most experiments are presented as fold increase in basal or control values. To compare the different experimental situations, 1-way or 2-way ANOVA was used, depending on the experiments. Pairwise comparisons were performed using Fisher's least significant difference method. The Dunnett test was used to analyze the changes in respect to basal values. All tests were two-tailed, and a value of $p<0.5$ was considered statistically significant.

\section{Results}

3.1. Glucose Oxidase Induced Cellular Senescence in Renal Mouse Cortical Tubule (MCT) Cells Increasing the ILK Expression and Activity. MCT cells were treated with $2.5 \mathrm{mU} / \mathrm{mL}$ GOx for 24,48 , and $72 \mathrm{~h}$, to induce oxidant stress. GOx induced a time-dependent increase in oxidative damage, which was evaluated quantifying the formation of 4-hydroxynonenal protein adducts by western blot (Figure 1(a)). Protein expression of senescence genes 


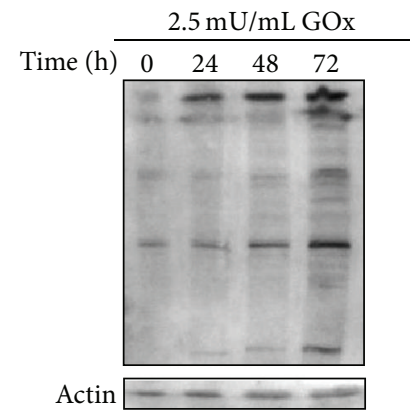

(a)

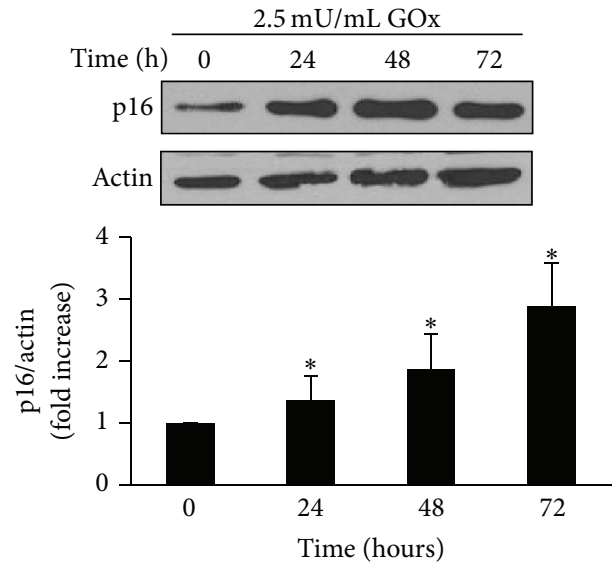

(b)

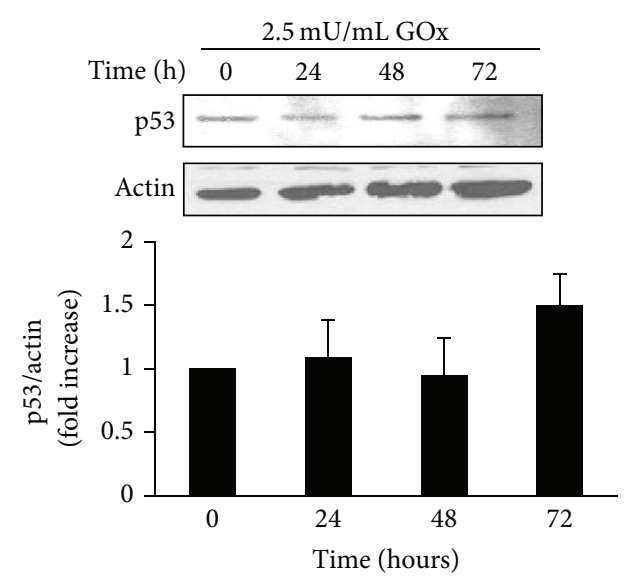

(c)
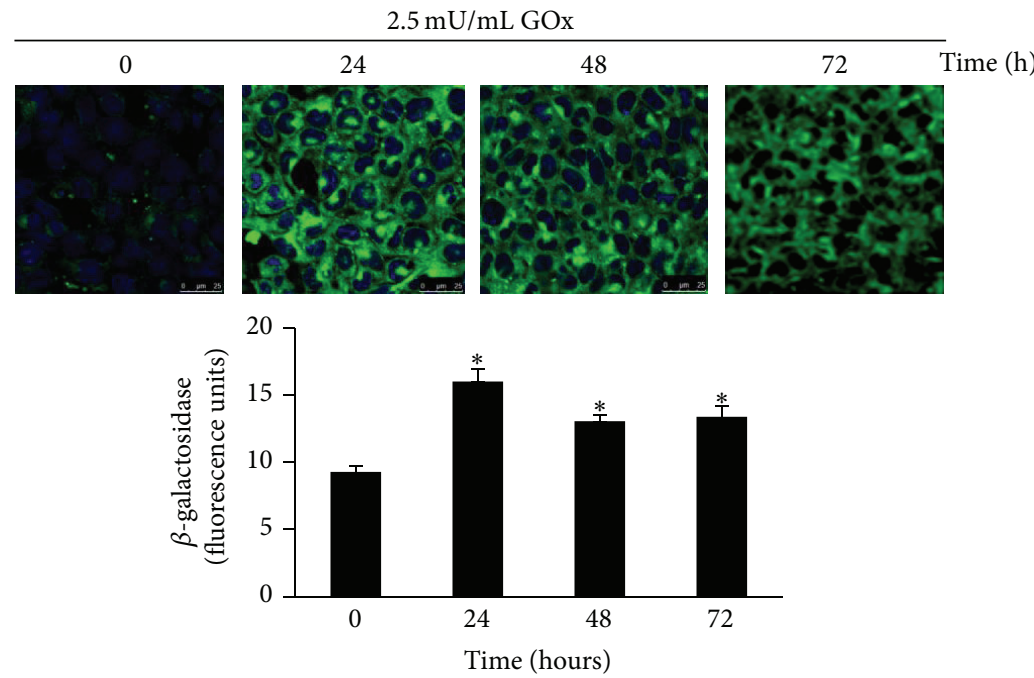

(d)

FIGURE 1: GOx induces senescence in wild-type mouse cortical tubule (MCT) cells. MCT cells were treated with $2.5 \mathrm{mU} / \mathrm{mL}$ GOx for 24,48 , or $72 \mathrm{~h}$. (a) 4-Hydroxy-2-nonenal proteins adducts were analyzed by western blot. (b) p16 and (c) p53 protein expressions were analyzed by western blot. A representative blot is shown in each case. Bar graphs represent the densitometric analysis of the bands. The results are expressed as densitometric units and are the mean \pm s.e.m. from six different experiments. (d) SA- $\beta$-GAL activity was analyzed by confocal microscopy using the fluorescent substrate C12FDG. A representative experiment is shown. Bar graph represents the analysis of the fluorescence from five different experiments and the mean \pm s.e.m. is expressed as fluorescence units. ${ }^{*} p<0.05$ versus control (time 0 ).

was evaluated by western blot. Results showed a timedependent increase in p16 expression (Figure 1(b)), whereas no significant changes were found in p53 expression (Figure $1(\mathrm{c})$ ). GOx also increased SA- $\beta$-GAL activity detected with confocal microscopy, indicating an increase in the percentage of senescent cells $24 \mathrm{~h}$ after GOx treatment (Figure $1(\mathrm{~d})$ ).

Next, to analyze whether there was a link between the increase in ILK and the induction of senescence, we overexpressed ILK on MCT cells by transfection with a plasmid 


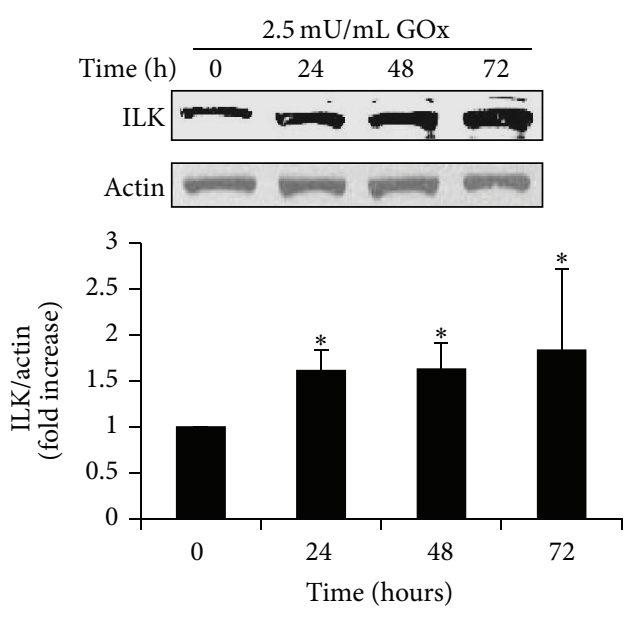

(a)

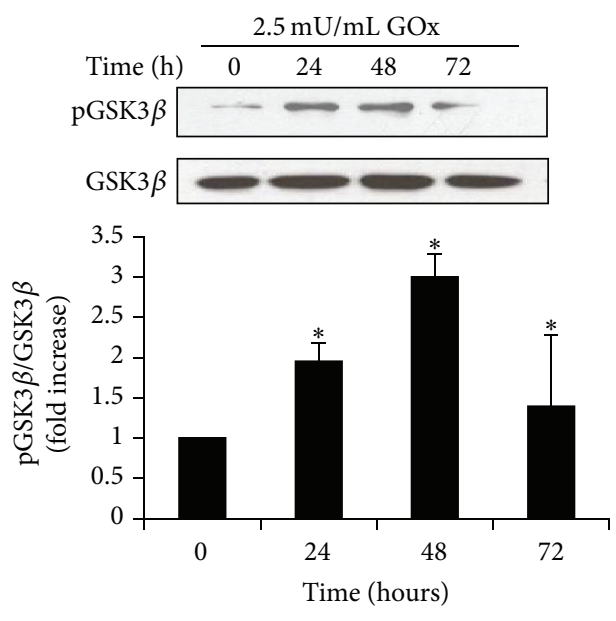

(b)

FIGURE 2: GOx induces an increase in ILK protein expression and activity. MCT cells were treated with $2.5 \mathrm{mU} / \mathrm{mL}$ GOx for 24,48 , or $72 \mathrm{~h}$. (a) ILK and (b) phospho-GSK3 $\beta$ and GSK3- $\beta$ protein expression was analyzed by western blot. A representative blot is shown in each case. Bar graphs represent the densitometric analysis of the bands. The results are expressed as densitometric units and are the mean \pm s.e.m. from four different experiments. ${ }^{*} p<0.05$ versus control (time 0 ).

containing a wild-type ILK protein (WT-ILK). Figure 3(a) shows how the expression of ILK increases in MCT cells transfected with WT-ILK in a dose-dependent way. MCT cells overexpressing ILK also had a strong expression of senescence gene p16, even in the absence of oxidant stress (Figure 3(a)). Moreover, ILK expression was knocked down by transfecting cells with specific silLK and then treated with $2.5 \mathrm{mU} / \mathrm{mL}$ GOx for $48 \mathrm{~h}$. Transfection significantly reduced ILK mRNA expression, measured by RT-qPCR (Figure 3(b)), and also the protein content, measured by western blot (Figure 3(c)). Cells transfected with siILK did not show the expected increase in p16 expression after GOx treatment compared to cells transfected with scRNA (Figure 3(c)). Both results allow establishing a direct link between the increase in ILK protein content and increased senescence gene p16 expression.

In parallel, we analyzed the effect of oxidant stress on ILK expression and activity and found that GOx induced a significant increase in the protein expression at all times examined (Figure 2(a)). GOx also induced an increase in the ILK activity evaluated as the phosphorylation of its substrate GSK-3 $\beta$, as shown in Figure 2(b), without changes in the protein content of total GSK-3 $\beta$.

3.2. Glucose Oxidase Reduced the Expression of the Gene Klotho in MCT Cells. MCT cells were treated with $2.5 \mathrm{mU} / \mathrm{mL}$ GOx for 24,48 , and $72 \mathrm{~h}$, and Klotho mRNA expression was analyzed by RT-real time PCR. We found that oxidative stress significantly reduced the mRNA expression of Klotho gene $24 \mathrm{~h}$ after GOx addition (Figure 4(a)). To analyze whether the reduction in Klotho expression could be related to the increase in senescence gene p16, MCT cells were transfected with a plasmid containing Klotho protein. The transfection of pEF1-Klotho induced a strong increment in Klotho mRNA expression compared with transfection of
pEF1-Empty (Figure 4(b)). The highest expression of Klotho remained until $72 \mathrm{~h}$ after transfection (data not shown).

After transfection, cells were treated with $2.5 \mathrm{mU} / \mathrm{mL}$ GOx and p16 expression was evaluated by western blot. Cells transfected with the empty vector (pEF1-Empty) responded to GOx treatment increasing p16 expression, as expected, whereas cells overexpressing Klotho protein (pEF-1-Klotho) did not increase the expression of senescence gene p16 (Figure 4(c)).

3.3. Reduced Klotho Expression Depended on the Increase in ILK Expression in Response to Oxidative Stress. To analyze whether there was a relationship between the reduction of Klotho and the increase in ILK expression, we analyzed Klotho expression in MCT cells transfected with specific siRNA against ILK. Cells transfected with silLK showed a stronger reduction in ILK mRNA expression (Figure 5(a)) and a stronger increase in Klotho mRNA expression (Figure 5(b)) than cells transfected with the unspecific siRNA (scRNA), which were evaluated by RT-qPCR.

In addition, this effect was confirmed by using a conditional ILK knockout mouse model (cKO-ILK). After treatment with TX for several days, ILK deletion was confirmed by PCR (Figure 5(c)). ILK expression was reduced in renal cortex from cKO-ILK versus WT mice (Figure 5(d)). The reduction in ILK gene expression was parallel with a higher Klotho gene expression in cKO-ILK mice versus WT (Figure 5(e)), as we found in MCT cells.

Additionally, the protein content of senescence genes p53 and p16 was analyzed in the renal cortex isolated from cKO-ILK mice, finding lower expression than in WT mice (Figure 5(f)). Treatment of ILK and Senescence. To assess whether oxidative 


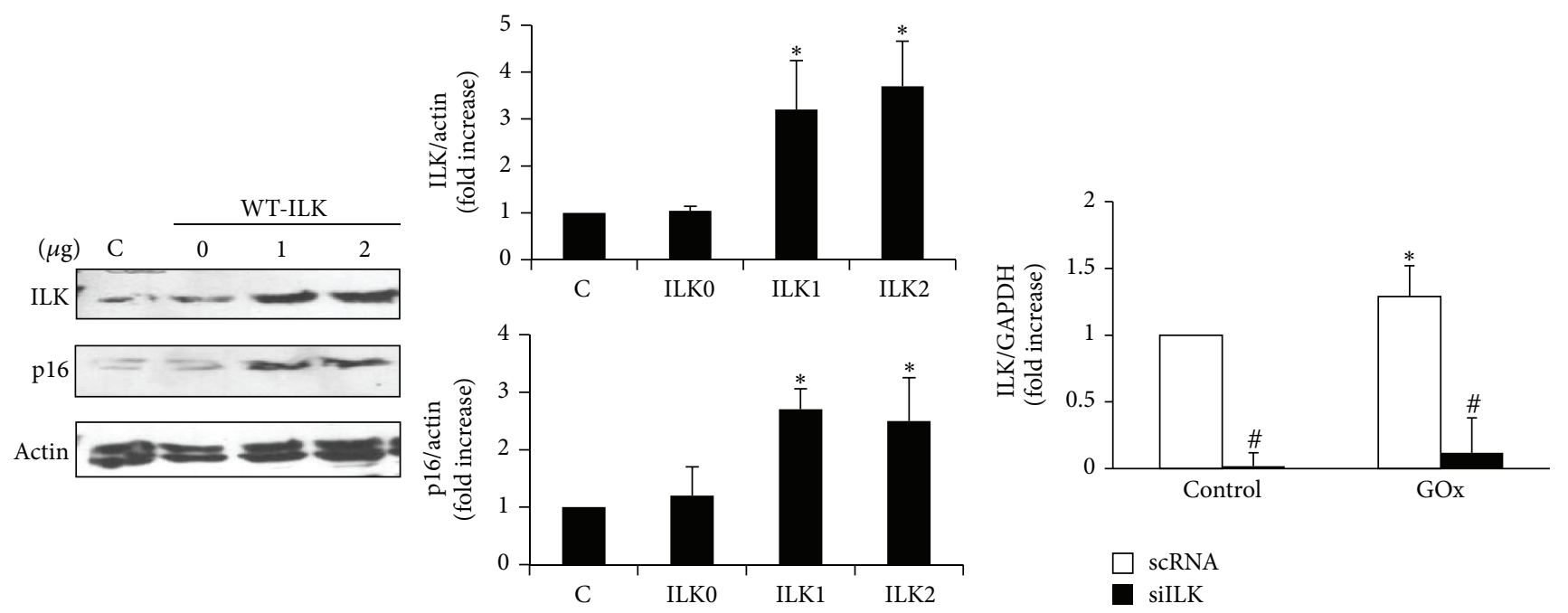

(a)

(b)
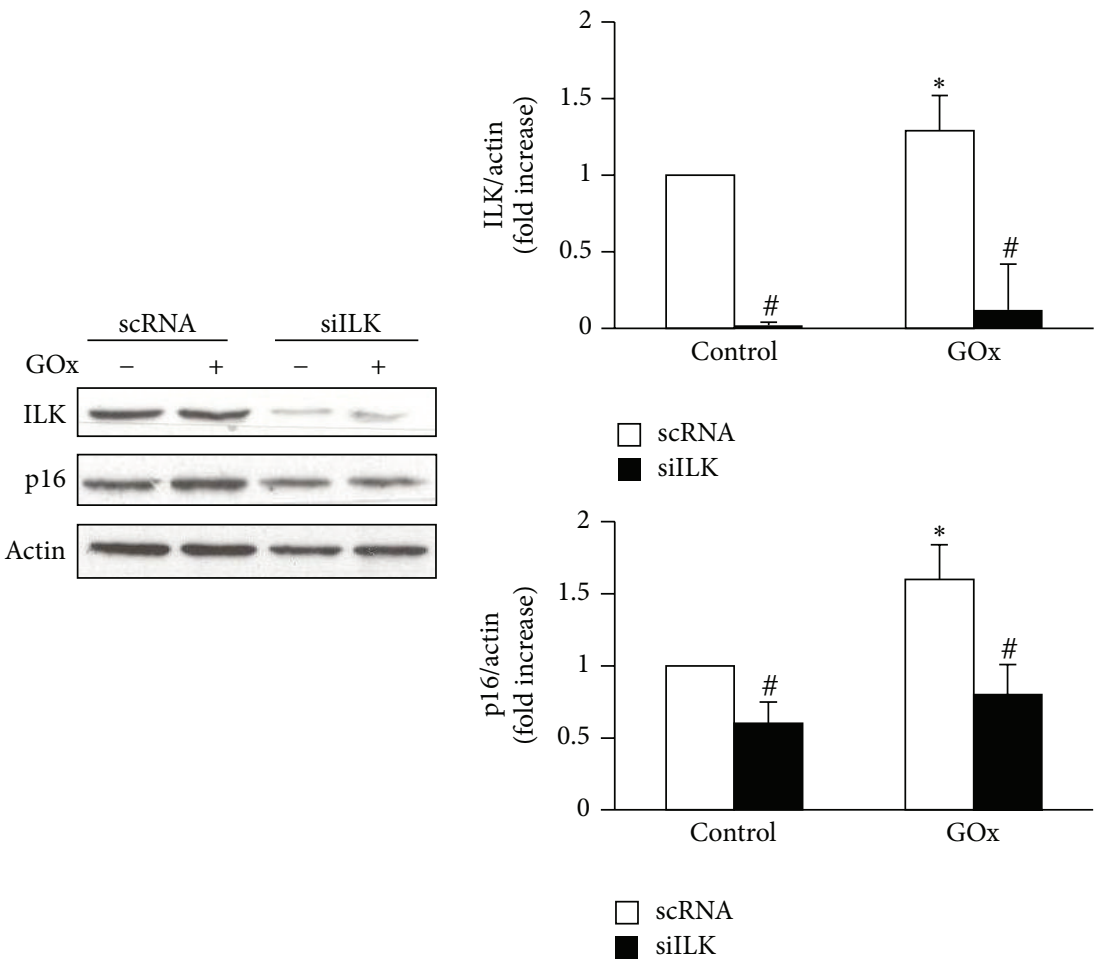

(c)

FIGURE 3: ILK mediates cellular senescence induced by GOx. (a) MCT cells were transfected with a plasmid coding for wild-type ILK protein (WT-ILK) at several doses $(0,1$, or $2 \mu \mathrm{g}$ ). ILK and p16 proteins were evaluated by western blot. (b, c) MCT were transfected with the specific siRNA for ILK (silLK) or unspecific scramble siRNA (scRNA) as control and then treated with $2.5 \mathrm{mU} / \mathrm{mL}$ of GOx for $48 \mathrm{~h}$. In those conditions, mRNA ILK was evaluated by RT and real time PCR (b) and ILK and p16 protein expression was evaluated by western blot (c). A representative blot is shown in each case. Bar graphs represent the densitometric analysis of the bands. The results are expressed as densitometric units and are the mean \pm s.e.m. of the mean from five different experiments. ${ }^{*} p<0.05$ versus control; ${ }^{*} p<0.05$ versus scRNA.

stress induces senescence in other cultured cells proceeding from kidney and whether the mechanisms involved were similar to those of MCT cells, HEK293T cells were treated with $2.5 \mathrm{mU} / \mathrm{mL}$ of GOx for 24, 48, and $72 \mathrm{~h}$. Then, ILK and p16 expressions were analyzed by western blot. Figure 6(a) shows that GOx induced an increased expression of both ILK and p16 with a similar pattern to the expression found in MCT cells. In addition, HEK293T cells were transfected with Klotho expression vector to analyze whether Klotho overexpression was able to inhibit the increase in p16 expression after GOx 


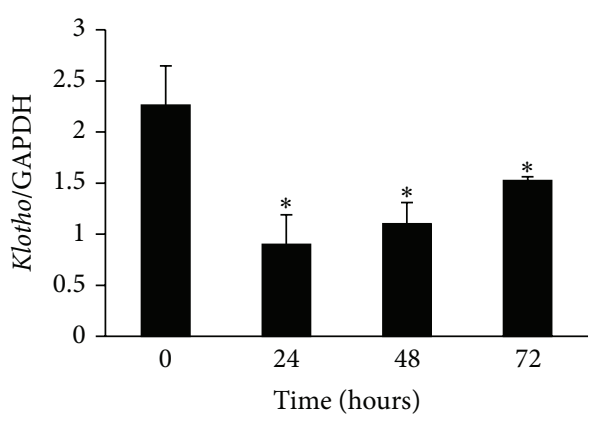

(a)

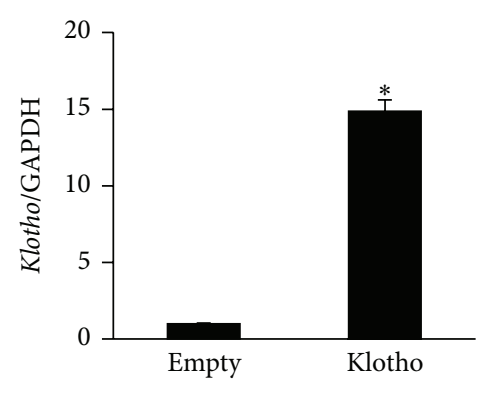

(b)

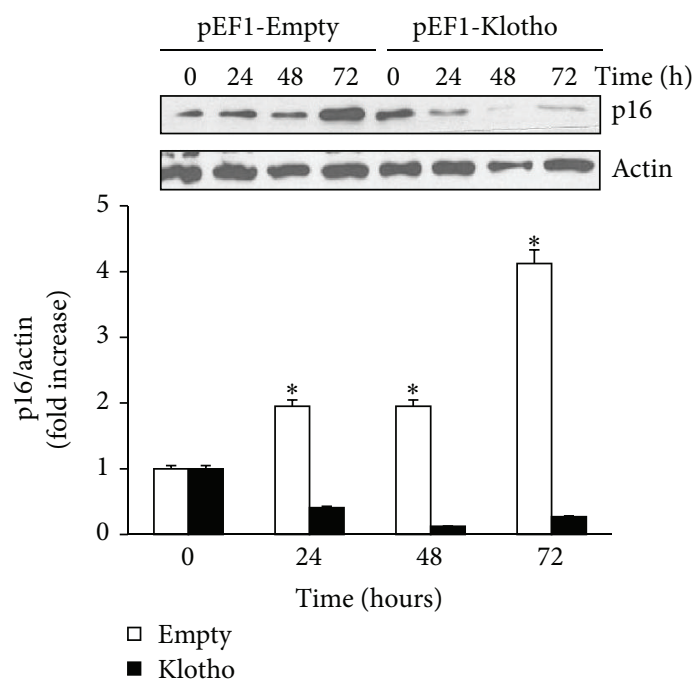

(c)

FIGURE 4: Antiaging gene Klotho is modulated by GOx and mediates cellular senescence induced by GOx. (a) MCT cells were treated with $2.5 \mathrm{mU} / \mathrm{mL}$ of GOx for 24, 48, and $72 \mathrm{~h}$ and mRNA Klotho expression was analyzed by RT and real time PCR. Bar graph represents the mean \pm s.e.m. from three different experiments. MCT cells were transfected with a plasmid containing Klotho protein (pEF1-Klotho) or with an empty vector (pEF1-Empty) as control, and (b) mRNA Klotho expression was analyzed by RT and real time PCR. Bar graph represents the mean \pm s.e.m. of three different experiments. (c) MTC cells transfected with Klotho protein were treated with $2.5 \mathrm{mU} / \mathrm{mL}$ of GOx for 24,48 , and $72 \mathrm{~h}$ and p16 protein expression was evaluated by western blot. A representative blot is shown. Bar graphs represent the densitometric analysis of the bands. The results are expressed as densitometric units and are the mean \pm s.e.m. from five different experiments. ${ }^{*} p<0.05$ versus control (time 0 ).

addition. Results shown in Figure 6(b) demonstrated that cells overexpressing Klotho did not present the expected increase in the senescence gene p16.

\section{Discussion}

The free-radical theory of aging is one of the most popular theories in aging research and the role of oxidative stress in cellular senescence has been extensively studied. Many stressor conditions, such as hyperosmolar stress [9] and advanced glycation end products [10], are able to induce premature senescence in renal cells by disrupting the balance between reactive oxygen species (ROS) generation and the activity of antioxidant systems. However, the mechanisms activated after the manifestation of oxidative stress, which lead to cellular senescence, are less known. For this reason, in this work, we explored some of the mechanisms which could be activated by oxidative stress to lead cells to senescence.
To induce a chronic oxidative stress, we used glucose oxidase, as previously described $[38,39]$. GOx is an enzyme, absent in mammalian cells [40], which converts oxygen to hydrogen peroxide, in a stoichiometrically simple 1:1 relationship, using glucose as substrate. Its product, D-gluconolactone, is metabolically inert $[41,42]$. The activity of GOx is stable and remains fully active over $24 \mathrm{~h}$. For this reason, we replaced the medium with fresh medium and GOx every $24 \mathrm{~h}$ [40]. In our experiment, GOx addition increases the oxidative damage of proteins in a time-dependent way. Hydrogen peroxide is well known as a tissue damage mediator in several pathological conditions. In the kidney, hydrogen peroxide is known to play an important role in the pathogenesis of ischemiareperfusion events in tubular cells [43], in CKD [44], and in several inflammatory kidney diseases $[45,46]$. Depending on the kidney environmental conditions, oxidative stress generated by hydrogen peroxide induces cell proliferation, apoptosis, and fibrosis [43, 47-49], leading to tissue damage. 


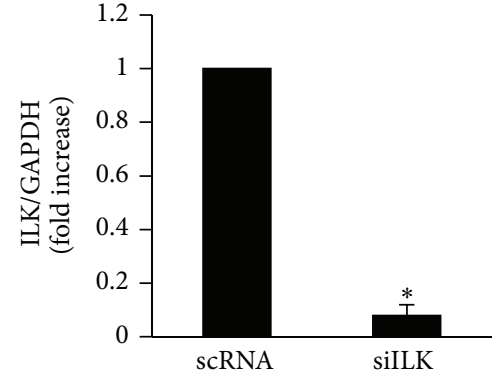

(a)

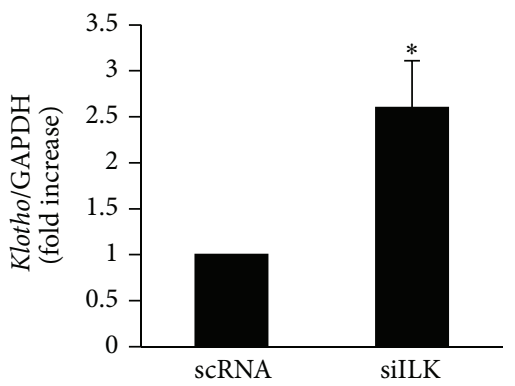

(b)

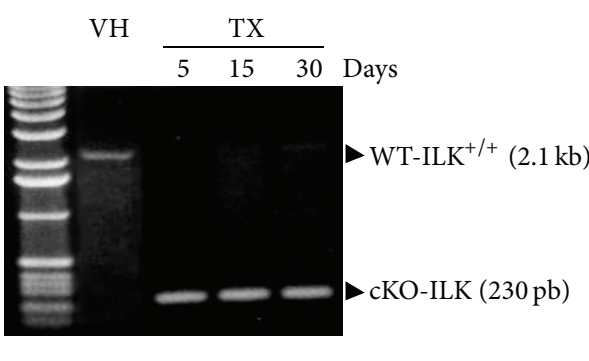

(c)

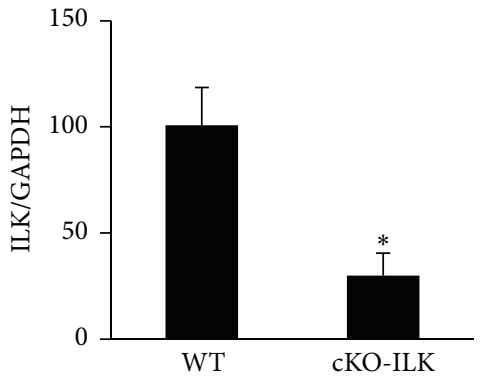

(d)

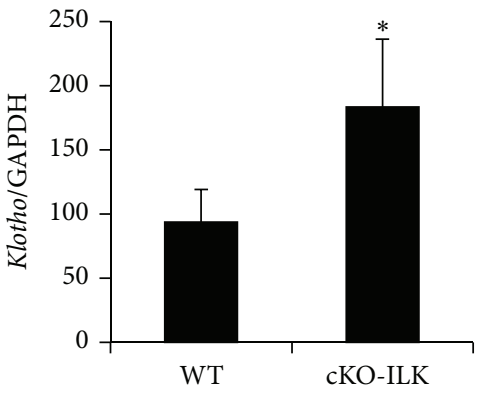

(e)
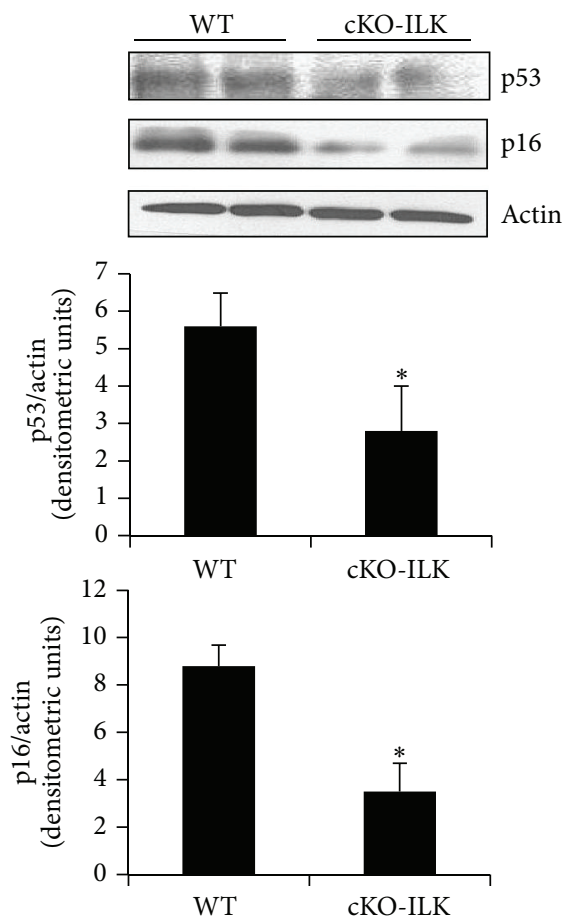

(f)

FIGURE 5: Increased ILK expression by GOx induced decrease in Klotho expression. (a, b) MCT cells were transfected with specific siRNA for ILK (siILK) or unspecific scramble siRNA (scRNA) as control. ILK (a) and Klotho (b) mRNA expression was evaluated by RT and real time PCR. Bar graph represents the mean \pm s.e.m. of three different experiments, and the results are expressed as densitometric units. (c) A conditional ILK knockout mouse model (cKO-ILK) was used and, after treatment with TX for several days, ILK deletion was confirmed versus VH treatment in those mice by PCR of genomic DNA isolated from kidney. ILK (d) and Klotho (e) mRNA expression was analyzed in kidney from WT and cKO-ILK mice by RT and real time PCR. Bar graph represents the mean \pm s.e.m. of 10 animals per group. (f) p53 and p16 protein expression was analyzed in kidney from WT and cKO-ILK mice by western blot. A representative blot is shown. Bar graphs represent the densitometric analysis of the bands. The results are expressed as densitometric units and are the mean \pm s.e.m. of 10 animals per group. ${ }^{*} p<0.05$ versus control (scRNA in panels (a)-(b) and WT in the rest panels). 

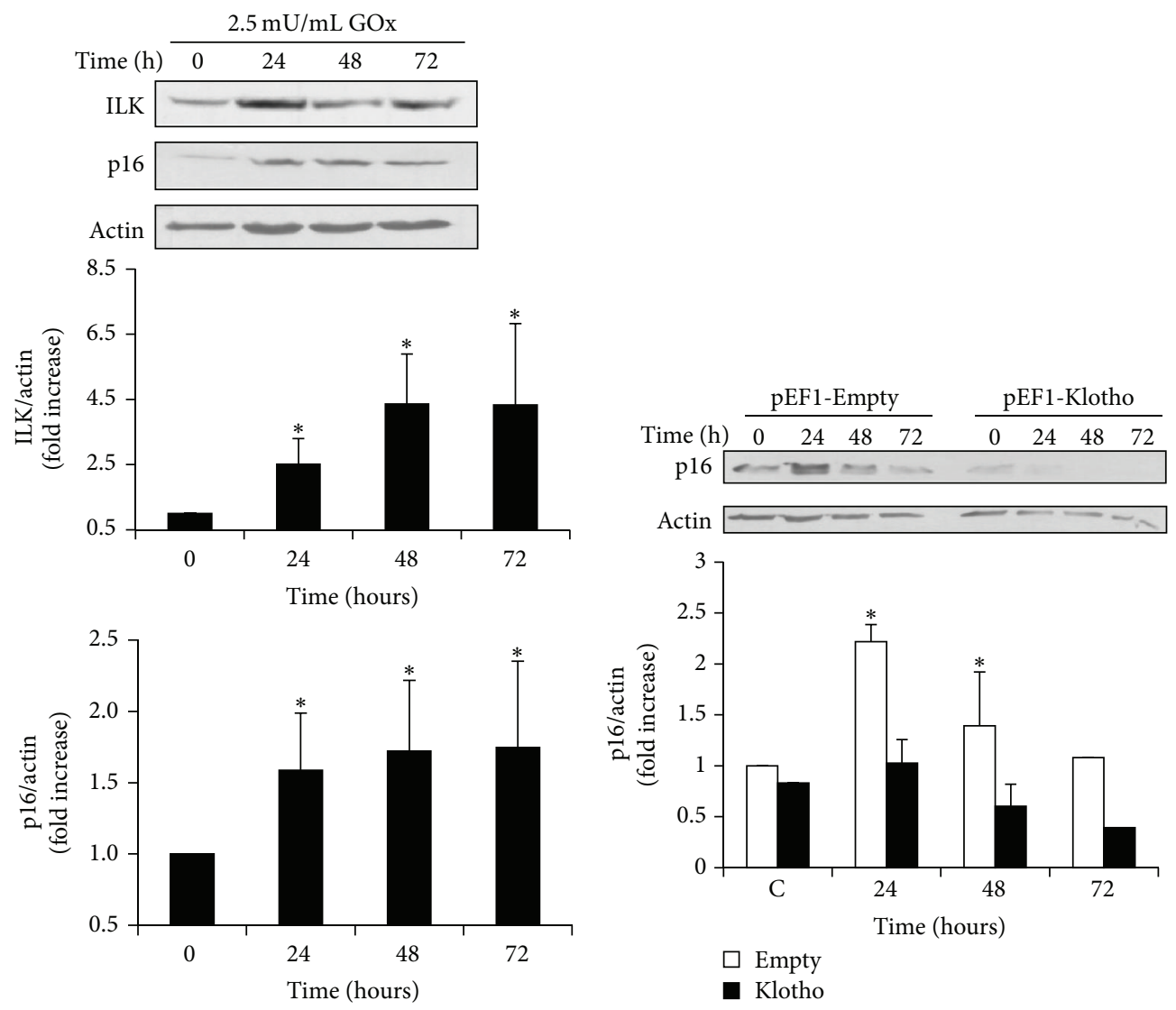

(a)

(b)

FIGURE 6: GOx induced senescence through ILK in other renal cells. HEK293T cells were treated with $2.5 \mathrm{mU} / \mathrm{mL}$ GOx for 24,48 , or $72 \mathrm{~h}$. (a) ILK and p16 protein expressions were analyzed by western blot. A representative blot is shown in each case. Bar graphs represent the densitometric analysis of the bands. The results are expressed as densitometric units and are the mean \pm s.e.m. from six different experiments. (b) HEK293T cells were transfected with Klotho protein (pEF1-Klotho, closed bars) or empty vector (pEF1-Empty, open bars) and then treated with $2.5 \mathrm{mU} / \mathrm{mL}$ of GOx for 24,48 , and $72 \mathrm{hs.} \mathrm{p16}$ protein expression was evaluated by western blot. A representative blot is shown. Bar graphs represent the densitometric analysis of the bands. The results are expressed as a percentage of control and are the mean \pm s.e.m. from five different experiments. ${ }^{*} p<0.05$ versus control or time 0 .

We hereby propose that a possible mechanism for tissue damage caused by hydrogen peroxide could be the induction of cellular senescence in renal cells. The accumulation of senescent cells in tissues has been identified as a mechanism involved in tissue dysfunction. In this regard, hydrogen peroxide is described to cause senescence in HK-2 tubular cells in a CKD experimental model [50], inducing cell loss. We found that oxidative stress induced by GOx increased senescence in MCT cells in culture $24 \mathrm{~h}$ after addition, which were identified to express SA- $\beta$-GAL activity. Cellular senescence is defined as an irreversible cell cycle arrest characterized by the expression of the cell cycle inhibitor p16 or/and the tumor suppressor p53 [51]. Immortal MCT cells under GOx treatment show an increase in p16 but not in p53 gene expression. The increase in the expression of p16 has been described as a robust biomarker for cellular senescence [52] and has been associated with many age-related diseases [53]. Both increased expression of p16 protein and increased SA- $\beta$ GAL activity allow us to confirm that prolonged exposition to GOx induced cellular aging in MCT cells.
Next step was to elucidate how oxidative stress leads to senescence. Recently, it has been reported that hydrogen peroxide increases TGF- $\beta 1$ expression through ILK in glomerular mesangial cells [39]. ILK is a component of the intracellular complex that links transmembrane integrins with the actin cytoskeleton and other intracellular signaling pathways [54]. ILK regulates proliferation, differentiation, and motility in many cell types and has recently been involved in cellular senescence $[55,56]$. For this reason, we analyzed whether oxidative stress due to hydrogen peroxide also increases ILK expression in MCT cells and found a significant increase after GOx treatment. ILK has a pseudokinase activity [57], which can be measured by the phosphorylation of one of its substrates, GSK-3 $\beta$ [58]. Besides, an increase in phospho-GSK-3 $\beta$ was found in MCT cells. In order to assess a direct relationship between the increase in ILK expression and activity and cellular senescence, ILK protein was overexpressed by transfecting MCT cells with a plasmid containing the wild-type ILK gene. ILK and p16 expression levels increased 3-fold in transfected cells as compared to 


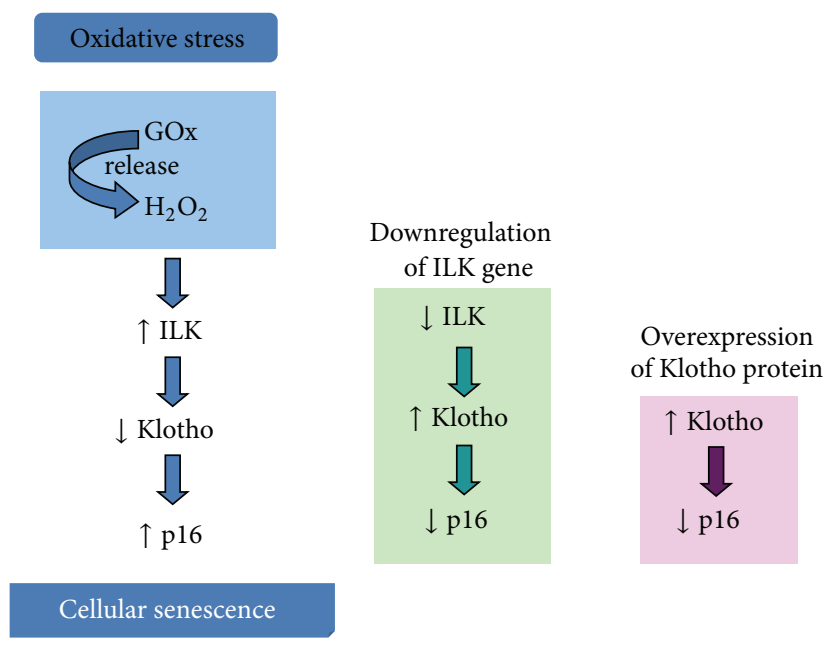

Figure 7: Proposed integrative mechanisms involved in cellular senescence induced by chronic oxidative stress in renal cells. Oxidative stress increases ILK activity and expression, which in turn reduces Klotho gene expression. Cells with reduced levels of Klotho are less protected from oxidative stress and undergo senescence.

nontransfected ones, even in the absence of oxidative stress. Moreover, MCT cells transfected with small interfering RNA against ILK to silence ILK expression did not undergo senescence despite the GOx addition. These results clearly indicate that ILK overexpression has a critical role in cellular senescence induced by oxidative stress. In accordance with this result, it has been described that genetic reduction of ILK in both C. elegans and Drosophila led to lifespan extension [59].

One of the antiaging factors most studied is the Klotho gene, which is expressed mainly in renal tubular cells; Klotho protein protects cells from apoptosis and senescence $[60,61]$ and from oxidative damage [62]. We analyzed the effect of oxidative damage on the expression of Klotho gene in MCT cells and found a reduction in Klotho mRNA expression. Klotho expression is downregulated in multiple pathological conditions, such as hyperlipidemia, hypertension, and CKD $[63,64]$. A significant correlation was found between Klotho levels and oxidative damage in the serum of CKD patients [65]. Our results show that chronic oxidative stress induces a significant reduction in Klotho expression, which could lead to senescence, since cells with an ectopic overexpression of Klotho protein did not undergo senescence after GOx addition.

Therefore, we explored whether the reduction of Klotho protein was linked to the increase in ILK under oxidative stressing conditions. For this purpose, we performed two different experimental approaches. First, we downregulated ILK expression by transfection with siILK and found an increase in the transcription of Klotho gene. Second, we analyzed the Klotho expression in a conditional KO of ILK animal model, as previously reported [37]. Conditional KOILK mice showed a strong reduction in renal ILK expression, which was accompanied with an increase in the Klotho expression as compared with WT mice. Finally, p16 and p53 senescence gene expression was analyzed in the renal cortex from these animals. Results showed a significant reduction in the expression of both genes.
In accordance with these results, a work performed in C. elegans has recently reported that genetic reduction in ILK induced stress response genes related to antioxidant response and heat shock proteins [60]. We hereby propose that the reduction of ILK expression induces Klotho gene as a mechanism of stress response. Klotho protein decreases with age [66] and in many age-related diseases [67], but there are few works about the transcriptional regulation of the Klotho gene. Among these, it has been described that the hypermethylation of Klotho gene promoter increases with age, reducing its expression [68]. Similar results were found in HEK 293 T cells, suggesting that ILK plays an important role in renal aging.

\section{Conclusion}

We conclude that chronic oxidative stress induces senescence in renal cells by increasing ILK activity and expression, which in turn reduces Klotho gene expression. Cells with reduced levels of Klotho are less protected from oxidative stress and undergo senescence (Figure 7).

Evidence suggesting ILK as a novel downregulator of Klotho gene expression is presented here. Further experiments will be necessary to analyze the potential therapeutic implications of the inhibition of ILK in age-related renal pathologies.

\section{Disclosure}

All the authors are part of Programa Redes REDinREN from the FIS (RD12/0021/0006) and Fibroteam, Community of Madrid, Spain.

\section{Conflict of Interests}

The authors declare that there is no conflict of interests regarding the publication of this paper. 


\section{Authors' Contribution}

Gemma Olmos and María Piedad Ruíz-Torres have the same contribution.

\section{Acknowledgments}

The authors would like to thank Dr. Makoto Kuro-O from the University of Texas Southwestern Medical Center (Dallas, TX, USA) for providing them with Klotho transfection vectors; Dr. Shoukat Dedhar, University of British Columbia (Vancouver, Canada, USA) for the cKO-ILK mouse model and the WT-ILK plasmid; and Dr. Ricardo J. Bosch from the University of Alcalá of Madrid (Madrid, Spain) for wild-type mouse cortical tubule (MCT) cells. This work was supported by grants from the Fondo de Investigaciones Sanitarias (FIS) (Grants: PI13/02270, PI13/00336), Networks Program REDinREN from the FIS (Grant REDinREN: RD12/0021/0006), and the Community of Madrid (FIBROTEAM). Nuria TroyanoSuárez (BES-2009-029413) and María del Nogal-Avila (SAF 2007-623471) were supported by a Fellowship from the Spanish Ministry of Education and Science. Susana López-Ongil holds a contract from the Research Stabilization Program of FIS (CES07/032).

\section{References}

[1] D. G. A. Burton and V. Krizhanovsky, "Physiological and pathological consequences of cellular senescence," Cellular and Molecular Life Sciences, vol. 71, no. 22, pp. 4373-4386, 2014.

[2] L. Hayflick and P. S. Moorhead, "The serial cultivation of human diploid cell strains," Experimental Cell Research, vol. 25, no. 3, pp. 585-621, 1961.

[3] C. B. Harley, A. B. Futcher, and C. W. Greider, "Telomeres shorten during ageing of human fibroblasts," Nature, vol. 345, no. 6274 , pp. $458-460,1990$.

[4] A. S. IJpma and C. W. Greider, "Short telomeres induce a DNA damage response in Saccharomyces cerevisiae," Molecular Biology of the Cell, vol. 14, no. 3, pp. 987-1001, 2003.

[5] M. Serrano, A. W. Lin, M. E. McCurrach, D. Beach, and S. W. Lowe, "Oncogenic ras provokes premature cell senescence associated with accumulation of p53 and p16(INK4a)," Cell, vol. 88, no. 5, pp. 593-602, 1997.

[6] C. Wang, D. Jurk, M. Maddick, G. Nelson, C. Martin-ruiz, and T. Von Zglinicki, "DNA damage response and cellular senescence in tissues of aging mice," Aging Cell, vol. 8, no. 3, pp. 311-323, 2009.

[7] O. Toussaint, E. E. Medrano, and T. von Zglinicki, "Cellular and molecular mechanisms of stress-induced premature senescence (SIPS) of human diploid fibroblasts and melanocytes," Experimental Gerontology, vol. 35, no. 8, pp. 927-945, 2000.

[8] Y.-H. Wei and H.-C. Lee, "Oxidative stress, mitochondrial DNA mutation, and impairment of antioxidant enzymes in aging," Experimental Biology and Medicine, vol. 227, no. 9, pp. 671-682, 2002.

[9] M. del Nogal-Avila, N. Troyano-Suárez, L. Calleros et al., "Hyperosmolarity induced by high glucose promotes senescence in human glomerular mesangial cells," The International Journal of Biochemistry \& Cell Biology, vol. 54, pp. 98-110, 2014.

[10] M. del Nogal-Ávila, N. Troyano-Suárez, P. Román-García et al., "Amadori products promote cellular senescence activating insulin-like growth factor-1 receptor and down-regulating the antioxidant enzyme catalase," The International Journal of Biochemistry and Cell Biology, vol. 45, no. 7, pp. 1255-1264, 2013.

[11] G. P. Dimri, X. Lee, G. Basile et al., "A biomarker that identifies senescent human cells in culture and in aging skin in vivo," Proceedings of the National Academy of Sciences of the United States of America, vol. 92, no. 20, pp. 9363-9367, 1995.

[12] Q. Chen and B. N. Ames, "Senescence-like growth arrest induced by hydrogen peroxide in human diploid fibroblast F65 cells," Proceedings of the National Academy of Sciences of the United States of America, vol. 91, no. 10, pp. 4130-4134, 1994.

[13] D. C. Radisky, D. D. Levy, L. E. Littlepage et al., "Raclb and reactive oxygen species mediate MMP-3-induced EMT and genomic instability," Nature, vol. 436, no. 7047, pp. 123-127, 2005.

[14] T. Lu and T. Finkel, “Free radicals and senescence," Experimental Cell Research, vol. 314, no. 9, pp. 1918-1922, 2008.

[15] S. Macip, M. Igarashi, L. Fang et al., "Inhibition of p21-mediated ROS accumulation can rescue p21-induced senescence," The EMBO Journal, vol. 21, no. 9, pp. 2180-2188, 2002.

[16] P. Sun, N. Yoshizuka, L. New et al., "PRAK is essential for rasinduced senescence and tumor suppression," Cell, vol. 128, no. 2, pp. 295-308, 2007.

[17] F. Debacq-Chainiaux, E. Boilan, J. D. Le Moutier, G. Weemaels, and O. Toussaint, "P $38^{M A P K}$ in the senescence of human and murine fibroblasts," Advances in Experimental Medicine and Biology, vol. 694, pp. 126-137, 2010.

[18] K. Saito, N. Ishizaka, H. Mitani, M. Ohno, and R. Nagai, "Iron chelation and a free radical scavenger suppress angiotensin IIinduced downregulation of klotho, an anti-aging gene, in rat," FEBS Letters, vol. 551, no. 1-3, pp. 58-62, 2003.

[19] M. Mitobe, T. Yoshida, H. Sugiura, S. Shirota, K. Tsuchiya, and H. Nihei, "Oxidative stress decreases klotho expression in a mouse kidney cell line," Nephron-Experimental Nephrology, vol. 101, no. 2, pp. e67-e74, 2005.

[20] M. Yamamoto, J. D. Clark, J. V. Pastor et al., "Regulation of oxidative stress by the anti-aging hormone klotho," The Journal of Biological Chemistry, vol. 280, no. 45, pp. 38029-38034, 2005.

[21] I. Urakawa, Y. Yamazaki, T. Shimada et al., "Klotho converts canonical FGF receptor into a specific receptor for FGF23," Nature, vol. 444, no. 7120, pp. 770-774, 2006.

[22] D. Prié, L. Beck, P. Urena, and G. Friedlander, "Recent findings in phosphate homeostasis," Current Opinion in Nephrology and Hypertension, vol. 14, no. 4, pp. 318-324, 2005.

[23] H. Kurosu, M. Yamamoto, J. D. Clark et al., "Suppression of aging in mice by the hormone Klotho," Science, vol. 309, no. 5742, pp. 1829-1833, 2005.

[24] C. Wu and S. Dedhar, "Integrin-linked kinase (ILK) and its interactors: a new paradigm for the coupling of extracellular matrix to actin cytoskeleton and signaling complexes," The Journal of Cell Biology, vol. 155, no. 3, pp. 505-510, 2001.

[25] A. B. Fielding and S. Dedhar, "The mitotic functions of integrinlinked kinase," Cancer and Metastasis Reviews, vol. 28, no. 1-2, pp. 99-111, 2009.

[26] P. C. McDonald, A. B. Fielding, and S. Dedhar, "Integrin-linked kinase-essential roles in physiology and cancer biology," Journal of Cell Science, vol. 121, no. 19, pp. 3121-3132, 2008.

[27] Z. Li, X. Chen, Y. Xie et al., "Expression and significance of integrin-linked kinase in cultured cells, normal tissue, and diseased tissue of aging rat kidneys," Journals of Gerontology Series A: Biological Sciences and Medical Sciences, vol. 59, no. 10, pp. 984-996, 2004. 
[28] X. Chen, Z. Li, Z. Feng et al., "Integrin-linked kinase induces both senescence-associated alterations and extracellular fibronectin assembly in aging cardiac fibroblasts," Journals of Gerontology, Series A, Biological Sciences and Medical Sciences, vol. 61, no. 12, pp. 1232-1245, 2006.

[29] T. P. Haverty, C. J. Kelly, W. H. Hines et al., "Characterization of a renal tubular epithelial cell line which secretes the autologous target antigen of autoimmune experimental interstitial nephritis.," The Journal of Cell Biology, vol. 107, no. 4, pp. 1359-1368, 1988.

[30] A. Ortega, D. Rámila, J. A. Ardura et al., "Role of parathyroid hormone-related protein in tubulointerstitial apoptosis and fibrosis after folic acid-induced nephrotoxicity," Journal of the American Society of Nephrology, vol. 17, no. 6, pp. 1594-1603, 2006.

[31] D. J. Kurz, S. Decary, Y. Hong, and J. D. Erusalimsky, "Senescence-associated $\beta$-galactosidase reflects an increase in lysosomal mass during replicative ageing of human endothelial cells," Journal of Cell Science, vol. 113, no. 20, pp. 3613-3622, 2000.

[32] R. Ortega-Velázquez, M. L. Díez-Marqués, M. P. Ruiz-Torres, M. González-Rubio, M. Rodríguez-Puyol, and D. Rodríguez Puyol, "Arg-Gly-Asp-Ser (RGDS) peptide stimulates transforming growth factor betal transcription and secretion through integrin activation," The FASEB Journal, vol. 17, no. 11, pp. 15291531, 2003.

[33] H. Kurosu, Y. Ogawa, M. Miyoshi et al., "Regulation of fibroblast growth factor-23 signaling by Klotho," The Journal of Biological Chemistry, vol. 281, no. 10, pp. 6120-6123, 2006.

[34] L. Terpstra, J. Prud'Homme, A. Arabian et al., "Reduced chondrocyte proliferation and chondrodysplasia in mice lacking the integrin-linked kinase in chondrocytes," The Journal of Cell Biology, vol. 162, no. 1, pp. 139-148, 2003.

[35] N. Mijimolle, J. Velasco, P. Dubus et al., "Protein farnesyltransferase in embryogenesis, adult homeostasis, and tumor development," Cancer Cell, vol. 7, no. 4, pp. 313-324, 2005.

[36] B. Herranz, S. Márquez, B. Guijarro et al., "Integrin-linked kinase regulates vasomotor function by preventing endothelial nitric oxide synthase uncoupling: role in atherosclerosis," Circulation Research, vol. 110, no. 3, pp. 439-449, 2012.

[37] I. Serrano, M. L. Díez-Marqués, M. Rodríguez-Puyol et al., "Integrin-linked kinase (ILK) modulates wound healing through regulation of hepatocyte growth factor (HGF)," Experimental Cell Research, vol. 318, no. 19, pp. 2470-2481, 2012.

[38] S. López-Ongil, M. Saura, C. Zaragoza et al., "Hydrogen peroxide regulation of bovine endothelin-converting enzyme1," Free Radical Biology and Medicine, vol. 32, no. 5, pp. 406-413, 2002.

[39] M. Gonzalez-Ramos, S. de Frutos, M. Griera et al., "Integrinlinked kinase mediates the hydrogen peroxide-dependent transforming growth factor- $\beta 1$ up-regulation," Free Radical Biology and Medicine, vol. 61, pp. 416-427, 2013.

[40] S. Mueller, G. Millonig, and G. N. Waite, "The GOX/CAT system: a novel enzymatic method to independently control hydrogen peroxide and hypoxia in cell culture," Advances in Medical Sciences, vol. 54, no. 2, pp. 121-135, 2009.

[41] P. Kaczara, T. Sarna, and J. M. Burke, "Dynamics of $\mathrm{H}_{2} \mathrm{O}_{2}$ availability to ARPE-19 cultures in models of oxidative stress," Free Radical Biology and Medicine, vol. 48, no. 8, pp. 1064-1070, 2010.

[42] D. Rost, A. Welker, J. Welker et al., "Liver-homing of purified glucose oxidase: a novel in vivo model of physiological hepatic oxidative stress $\left(\mathrm{H}_{2} \mathrm{O}_{2}\right)$," Journal of Hepatology, vol. 46, no. 3, pp. 482-491, 2007.

[43] Y. Xu, S. Ruan, X. Wu, H. Chen, K. Zheng, and B. Fu, "Autophagy and apoptosis in tubular cells following unilateral ureteral obstruction are associated with mitochondrial oxidative stress," International Journal of Molecular Medicine, vol. 31, no. 3, pp. 628-636, 2013.

[44] M. Nakayama, K. Nakayama, W.-J. Zhu et al., "Polymorphonuclear leukocyte injury by methylglyoxal and hydrogen peroxide: a possible pathological role for enhanced oxidative stress in chronic kidney disease," Nephrology Dialysis Transplantation, vol. 23, no. 10, pp. 3096-3102, 2008.

[45] L. Baud and R. Ardaillou, "Reactive oxygen species: production and role in the kidney," The American Journal of PhysiologyRenal Fluid and Electrolyte Physiology, vol. 251, no. 5, pp. F765F776, 1986.

[46] Y. Y. Jang, J. H. Song, Y. K. Shin, E. S. Han, and C. S. Lee, "Protective effect of boldine on oxidative mitochondrial damage in streptozotocin-induced diabetic rats," Pharmacological Research, vol. 42, no. 4, pp. 361-371, 2000.

[47] C. Oudot, A.-D. Lajoix, B. Jover, and C. Rugale, "Oxydative stress and beneficial effect of sodium restriction on kidney damage associated with insulin resistance in rats," Annales de Cardiologie et d'Angeiologie, vol. 61, no. 3, pp. 162-166, 2012.

[48] E. Brouwer, P. A. Klok, M. G. Huitema, J. J. Weening, and C. G. M. Kallenberg, "Renal ischemia/reperfusion injury contributes to renal damage in experimental anti-myeloperoxidaseassociated proliferative glomerulonephritis," Kidney International, vol. 47, no. 4, pp. 1121-1129, 1995.

[49] C.-H. Hsing, W. Chou, J.-J. Wang, H.-W. Chen, and C.H. Yeh, "Propofol increases bone morphogenetic protein-7 and decreases oxidative stress in sepsis-induced acute kidney injury," Nephrology Dialysis Transplantation, vol. 26, no. 4, pp. 1162-1172, 2011.

[50] D. M. Small, N. C. Bennett, S. Roy, B. G. Gabrielli, D. W. Johnson, and G. C. Gobe, "Oxidative stress and cell senescence combine to cause maximal renal tubular epithelial cell dysfunction and loss in an in vitro model of kidney disease," NephronExperimental Nephrology, vol. 122, no. 3-4, pp. 123-130, 2013.

[51] J. Krishnamurthy, C. Torrice, M. R. Ramsey et al., "Ink4a/Arf expression is a biomarker of aging," The Journal of Clinical Investigation, vol. 114, no. 9, pp. 1299-1307, 2004.

[52] S. Ressler, J. Bartkova, H. Niederegger et al., "p16INK4A is a robust in vivo biomarker of cellular aging in human skin," Aging Cell, vol. 5, no. 5, pp. 379-389, 2006.

[53] W. R. Jeck, A. P. Siebold, and N. E. Sharpless, "Review: a metaanalysis of GWAS and age-associated diseases," Aging Cell, vol. 11, no. 5, pp. 727-731, 2012.

[54] S. Dedhar, "Cell-substrate interactions and signaling through ILK," Current Opinion in Cell Biology, vol. 12, no. 2, pp. 250-256, 2000.

[55] Z. Li, X. Chen, Y. Xie et al., "Expression and significance of integrin-linked kinase in cultured cells, normal tissue, and diseased tissue of aging rat kidneys," Journals of Gerontology, Series A: Biological Sciences and Medical Sciences, vol. 59, no. 10, pp. 984-996, 2004.

[56] X. Chen, Z. Li, Z. Feng et al., "Integrin-linked kinase induces both senescence-associated alterations and extracellular fibronectin assembly in aging cardiac fibroblasts," Journals of Gerontology-Series A Biological Sciences and Medical Sciences, vol. 61, no. 12, pp. 1232-1245, 2006. 
[57] K. R. Legate, E. Montañez, O. Kudlacek, and R. Fässler, "ILK, PINCH and parvin: the tIPP of integrin signalling," Nature Reviews Molecular Cell Biology, vol. 7, no. 1, pp. 20-31, 2006.

[58] M. Maydan, P. C. McDonald, J. Sanghera et al., "Integrin-linked kinase is a functional $\mathrm{Mn}^{2+}$-dependent protein kinase that regulates glycogen synthase kinase- $3 \beta$ (gsk- $3 \beta$ ) phosphorylation," PLoS ONE, vol. 5, no. 8, Article ID e12356, 2010.

[59] C. Kumsta, T.-T. Ching, M. Nishimura et al., "Integrin-linked kinase modulates longevity and thermotolerance in C. elegans through neuronal control of HSF-1," Aging Cell, vol. 13, no. 3, pp. 419-430, 2014.

[60] M. Ikushima, H. Rakugi, K. Ishikawa et al., "Anti-apoptotic and anti-senescence effects of Klotho on vascular endothelial cells," Biochemical and Biophysical Research Communications, vol. 339, no. 3, pp. 827-832, 2006.

[61] Y. Maekawa, M. Ohishi, M. Ikushima et al., "Klotho protein diminishes endothelial apoptosis and senescence via a mitogenactivated kinase pathway," Geriatrics and Gerontology International, vol. 11, no. 4, pp. 510-516, 2011.

[62] P. Ravikumar, J. Ye, J. Zhang et al., " $\alpha$-Klotho protects against oxidative damage in pulmonary epithelia," American Journal of Physiology-Lung Cellular and Molecular Physiology, vol. 307, no. 7, pp. L566-L575, 2014.

[63] H. Narumiya, S. Sasaki, N. Kuwahara et al., "HMG-CoA reductase inhibitors up-regulate anti-aging klotho mRNA via RhoA inactivation in IMCD3 cells," Cardiovascular Research, vol. 64, no. 2, pp. 331-336, 2004.

[64] Y. Wang and Z. Sun, "Klotho gene delivery prevents the progression of spontaneous hypertension and renal damage," Hypertension, vol. 54, no. 4, pp. 810-817, 2009.

[65] H. J. Oh, B. Y. Nam, M. J. Lee et al., "Decreased circulating Klotho levels in patients undergoing dialysis and relationship to oxidative stress and inflammation," Peritoneal Dialysis International, vol. 35, no. 1, pp. 43-51, 2015.

[66] S. Shahmoon, H. Rubinfeld, I. Wolf et al., "The aging suppressor Klotho: a potential regulator of growth hormone secretion," The American Journal of Physiology: Endocrinology and Metabolism, vol. 307, no. 3, pp. E326-E334, 2014.

[67] J. F. Navarro-González, J. Donate-Correa, M. M. de Fuentes, H. Pérez-Hernández, R. Martínez-Sanz, and C. Mora-FernáNdez, "Reduced Klotho is associated with the presence and severity of coronary artery disease," Heart, vol. 100, no. 1, pp. 34-40, 2014.

[68] G. D. King, D. L. Rosene, and C. R. Abraham, "Promoter methylation and age-related downregulation of Klotho in rhesus monkey," Age, vol. 34, no. 6, pp. 1405-1419, 2012. 


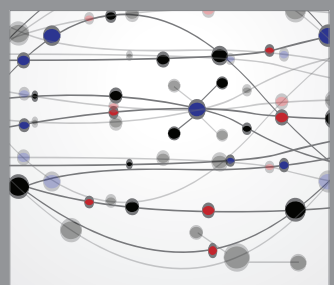

The Scientific World Journal
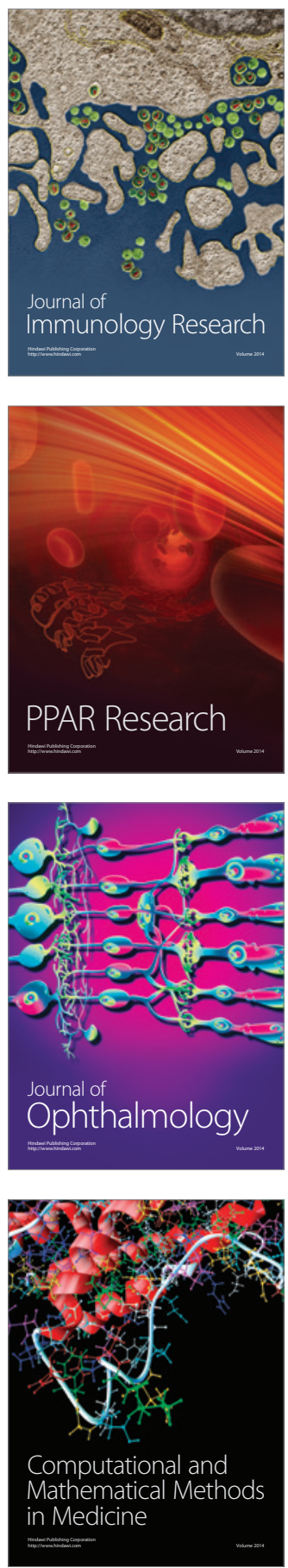

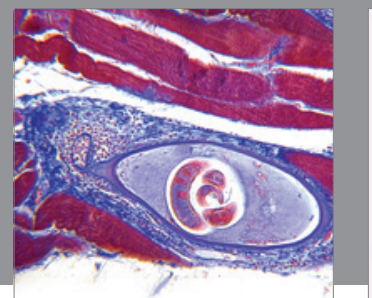

Gastroenterology

Research and Practice
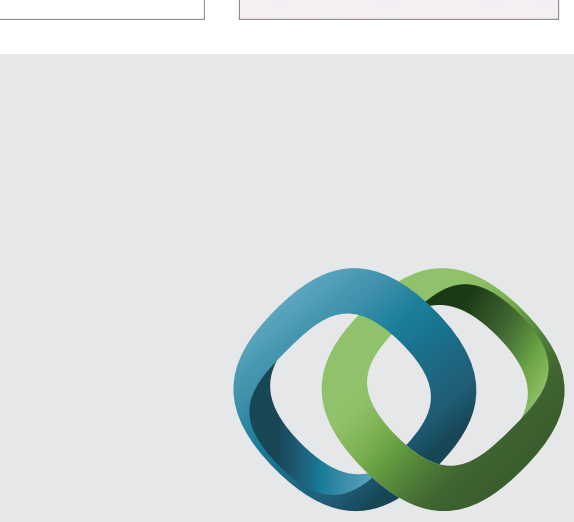

\section{Hindawi}

Submit your manuscripts at

http://www.hindawi.com
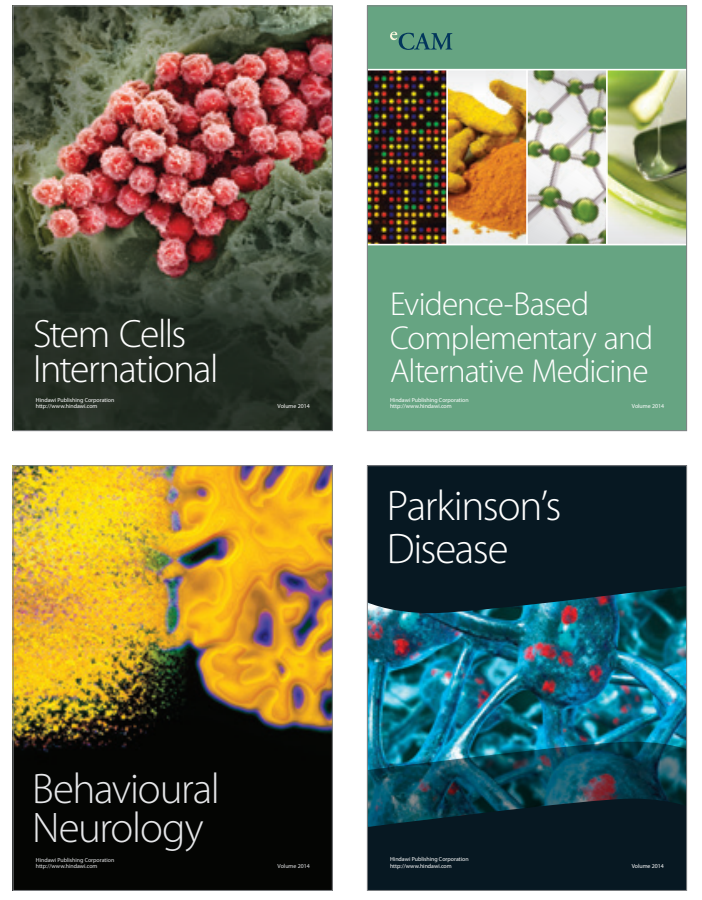
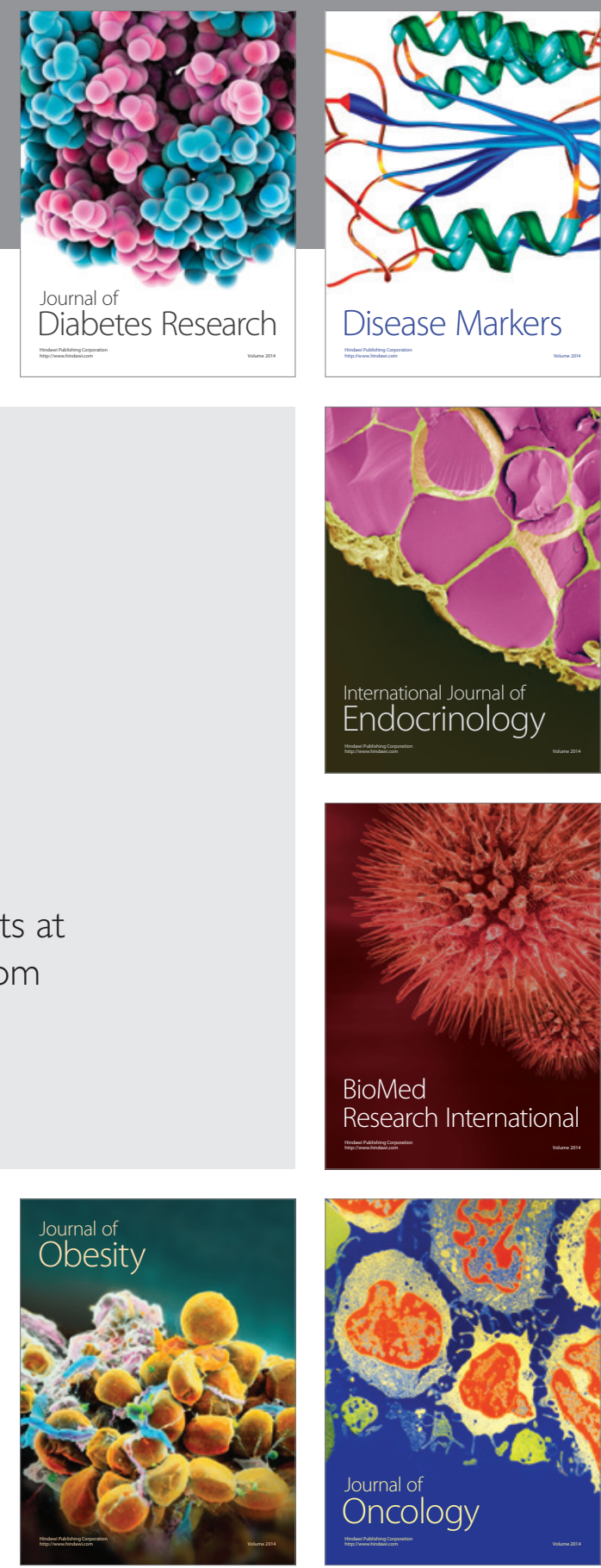

Disease Markers
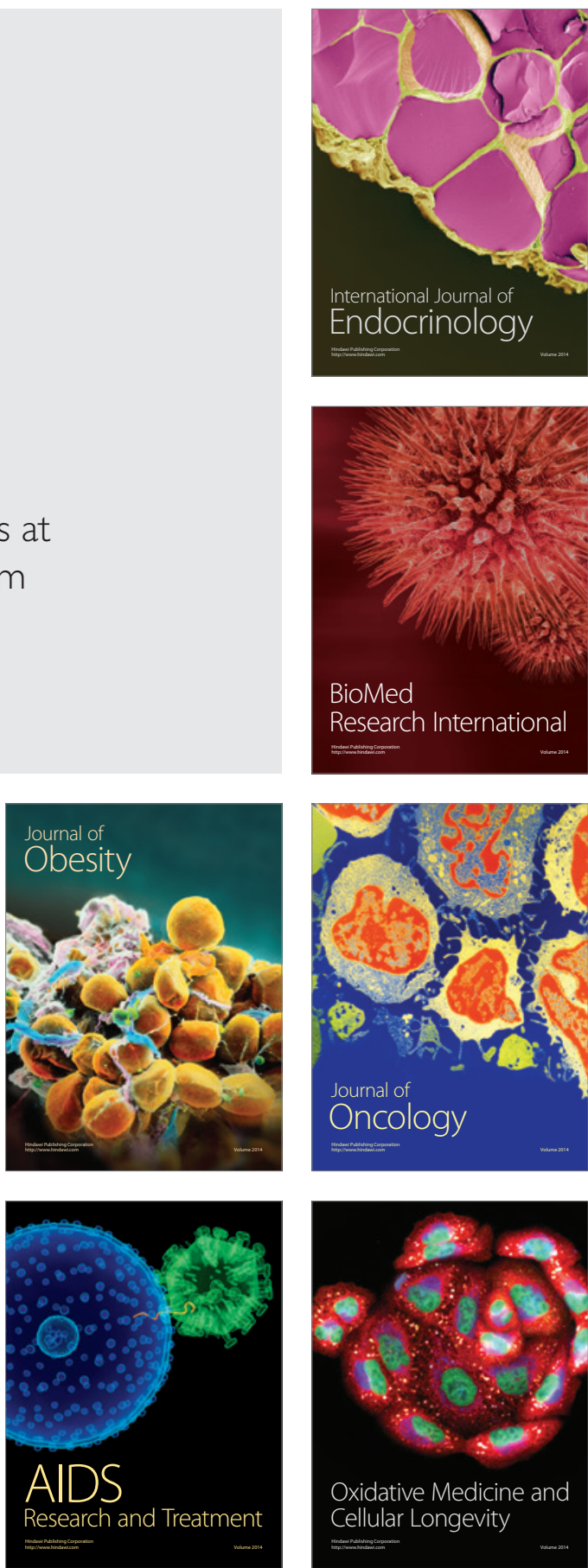